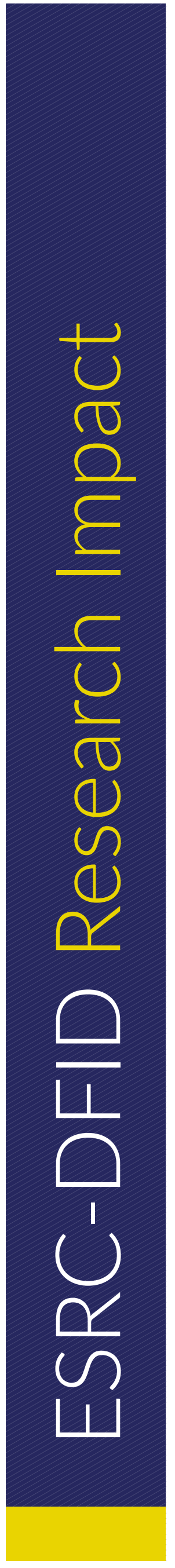

\title{
UNDERSTANDING DISPLACEMENT AND URBANISATION IN SOMALI CITIES
}

Somalia has one of the largest populations of internally displaced people (IDPs) in the world: an estimated 2.6 million in 2018. Yet little is known about the way displaced people experience flight and resettlement, how they learn to navigate their new city lives, and what measures they take to improve their security. The ESRC-DFID-funded 'Security on the Move' project captured the experiences of displaced people in four Somali cities and provided spaces for them to raise their concerns with policymakers. The study showed that land, tenure and labour insecurity consistently feature in their lives. Living conditions differed considerably depending on the duration of settlement, individuals' connection to local power-holders, and their gender. However, in all four cities, displaced people provided services within the expanding urban economies. Physical insecurity remained a threat, as people continued to experience evictions, domestic violence, crime, or threats posed by armed groups.

\section{THE CHALLENGE}

Somali cities are growing rapidly. In the context of ongoing conflicts, international intervention and attempts towards state reconstruction, little political attention has been given to the massive challenges of war-induced urbanisation. The numbers of displaced people remain high, and many move to cities where

they erect make-shift shelters in vacant urban spaces, squat in abandoned buildings, or join sprawling camps on the outskirts. These forms of in-migration increase population density and lead to unregulated expansion of cities. This increases pressure on the urban and rural environment, with rising demands for resource input (land, food, energy, water) and

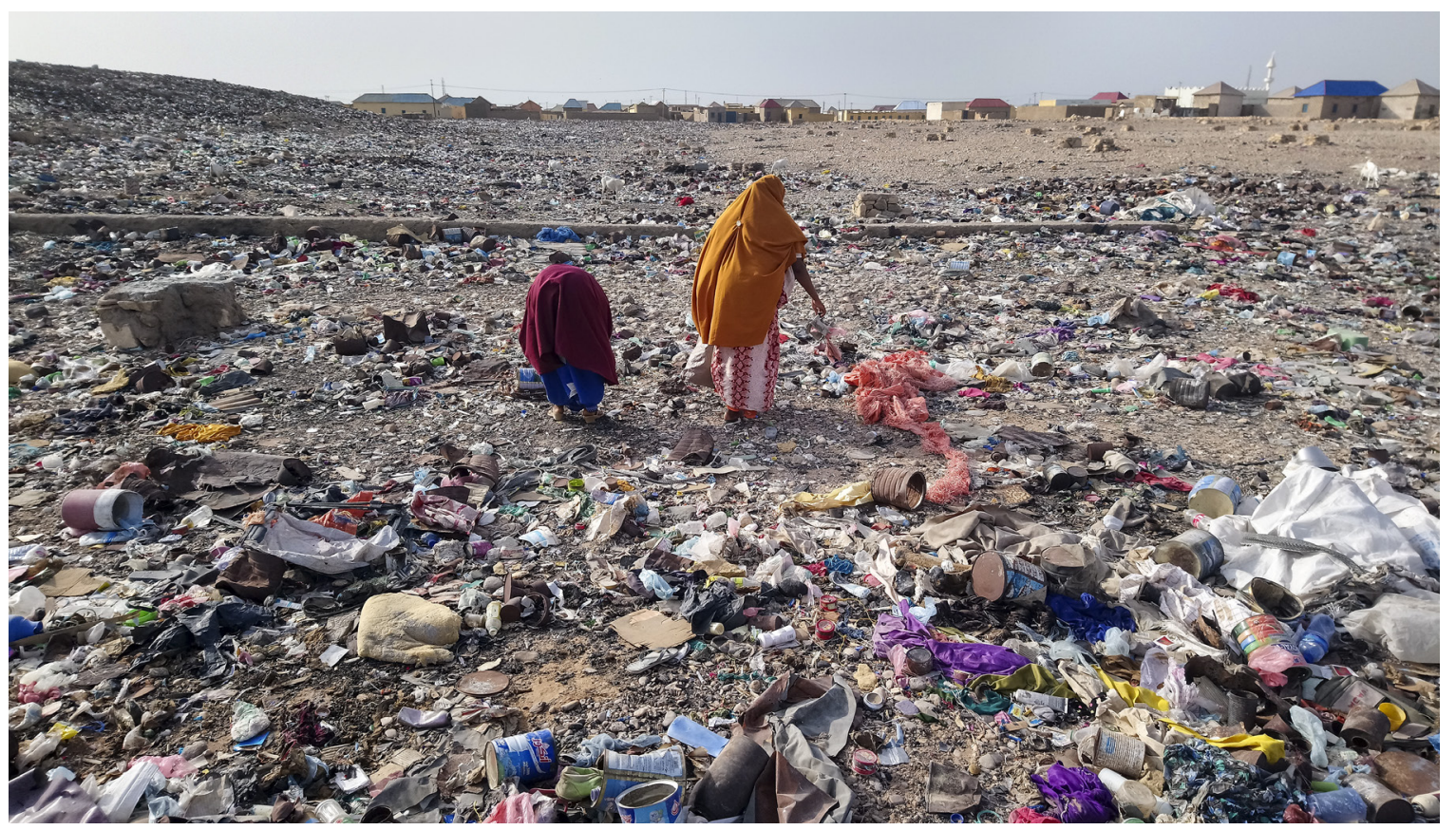

(c) Durham University (Picture taken by Yasiin, a displaced person in Bosaaso and project participant. A selection of the photos from the project exhibition is available at https://securityonthemove.co.uk/photo-exhibition/) 
waste output. Although state capacity varies across the politically fragmented Somali territories, there is generally little or no institutional experience of longterm urban planning.

\section{THE RESEARCH}

Durham University, together with Noragric and the Somali civil society organisation SOWELPA, used a combination of narrative interviews and photo-voice methods to gain insights into these vulnerabilities, and the strategies people develop to mitigate insecurity and rebuild their lives. The research engaged with 121 displaced people and 24 representatives of local authorities in the cities of Baidoa, Bosaaso, Hargeisa and Mogadishu. Forty internally displaced people were also trained and equipped to take photographs that document their everyday lives in order to present their perspectives on security and urbanisation across these cities. The majority of research participants explained how they had fled from a combination of violence and ecological shocks. Many described how recurrent droughts killed livestock, made farming impossible, deprived them of their means of subsistence, and caused the death of loved ones. A high number also spoke of ongoing violence, whether fighting between government-affiliated forces and al-Shabaab, violent harassment, extortion, or localised clashes between armed groups.

The study showed that extreme precarity and often also physical violence remain a defining feature of displacement, even after people settle in cities. Domestic violence was prevalent, and violence by militias, the state's security forces or criminals continues in all four cities, albeit in varying degrees. Crime, often committed by groups of young men, was the biggest security issue in Hargeisa and Bosaaso, while gun violence involving militias or governmental forces was prevalent in Mogadishu and to a lesser extent Baidoa. The location of settlements, types of accommodation, tenure and housing security depend on resources available to displaced people, negotiations between them and urban landowners, and on (potential) inclusion in planned resettlement schemes. In all four cities, displaced people contributed to the physical reconstruction, through clearance of land, the establishment of shelters, and by attracting businesses and humanitarian support. Over time, the settlements developed their own physical and social infrastructures including road and transport networks, and water and electricity supplies. These have successively integrated new settlements into the wider city. Displaced people also provide a huge (casual) workforce in the cities offering many services to residents including laundry, housework, portering, construction labour, and small trade.

\section{THE IMPACT}

The research has had a conceptual impact in that it has better informed policymakers and the directly affected communities. Through the organisation of exhibitions of the participants' photos and testimonies in all four cities, the project emphasised self-representation. It provided displaced people with the space and the means to communicate their concerns to policymakers, including the mayors of Bosaaso, Baidoa and Mogadishu, the Commissioner for IDPs and returnees in Baidoa, and representatives of international and national organisations (e.g. International Organization for Migration, United Nations Development Programme, Danish Refugee Council, and the UN Durable Solutions Office).

These exhibitions and research findings were covered by Somali media outlets, including radio, television, and online media. This coverage gave voice to those who are often ignored or actively silenced, and created awareness around the lives of displaced people. Furthermore, the work has had an academic impact as researchers were invited by the Rift Valley Institute (RVI) and the World Bank to contribute to further studies on migration and urbanisation. The lead researcher has also gone on to co-direct the RVI's Horn of Africa annual training course for high-level policymakers particularly focusing on mobility and urbanisation.

\section{FURTHER READING}

Bakonyi, J.; Chonka, P. and Stuvoy, K. (forthcoming, 2019) 'War and City-Making in Somalia: Property, Power and Disposable Lives', Political Geography, https://doi.org/10.1016/j.polgeo.2019.05.009

Internal Displacement Monitoring Centre, www.internal-displacement.org/countries/somalia Research briefs for the four cities, and updates on publications: http://securityonthemove.co.uk/ publications/

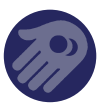

The 'Security on the Move' project was funded by ESRC-DFID Joint Fund for Poverty Alleviation Research and led by Jutta Bakonyi, Durham University, Noragric at the Norwegian University of Life Sciences, and the Somali civil society organisation SOWELPA, in collaboration with UN-Habitat.

\section{THE IMPACT INITIATIVE}

\section{For International Development Research}

The Impact Initiative seeks to connect policymakers and practitioners with the world-class social science research supported by the ESRC-DFID Strategic Partnership, maximising the uptake and impact of research from: (i) the Joint Fund for Poverty Alleviation Research, and (ii) the Raising Learning Outcomes in Education Systems Programme. We seek to identify synergies between these programmes and their grant holders, support them to exploit influencing and engagement opportunities, and facilitate mutual learning. The Impact Initiative is a collaboration between the Institute of Development Studies (IDS) and the University of Cambridge's Research for Equitable Access and Learning (REAL) Centre.

All content is available under the Open Government License v3.0, except where otherwise stated.

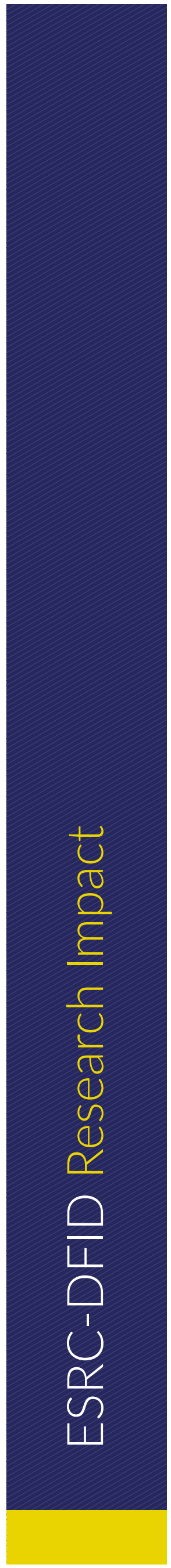

